ture, by applying the matter over a larger surface, in greater quantity, and for a longer period.

4th. That certain secondary affections are transferrible from the mother to the foetus in utero.

5th. That gonorrhoea depends upon a specific poison distinct from that of sy philis.

6 th. That gonorrbea is not followed by secondary symptoms.

Having thus brought before you the principal facts connected with the phenomena manifested by the syphilitic poison in the human constitution, so that they may be seen in one glance, I propose to say a few words on the theories which have been entertained by pathologists, in order to account for the mode of action of this particular poison; and you will recognise the practical importance of this part of our inquiry, when I remind you that upon the theory we adopt, with respect to the mode of action of any poison, must greatly depend the remedial means we should recommend to obviate its effects.

Mr. Hunter's theory is, that the poison of syphilis, when first inserted, acts simply on the part receiving it, and that no general absorption of the matter originally applied takes place. The first effect of the poison, he supposes, is to produce a specific inflammation locally; and that the result of this action is the formation of matter possessing similar properties to that which excited it. The virus produced in the pustule or ulcer of the primary sore, he imagines, at some uncertain period, becomes absorbed, and that the constitution is in this way contaminated.

When the virus had once entered the system in however small a dose (for he held that quantity had no influence), his opinion was that it circulated with the blood to the several tissues, stamping a diseased tendency upon certain of them : in some individuals, on the skin and throat only; in others, on these and on the bone-joints, \&c. as well. That having effected this mischief, the poison itself disappeared from the system, leaving, however, an inevitable disposition to disease in several of the tissues of the body. It is easy to understand that Mr. Hunter was constrained to hold some such hypothesis as this by his admission of certain supposed facts; viz., that the disease was only curable by mercury-that no two poisons could exist in the system at the same time-that the cure by mercury was effected by the poison of this mineral superseding that of syphilisthat the minutest possible quantity of the poison absorbed was sufficient to contaminate the whole system. It is absolutely necessary to bear in mind Mr. Hunter's firm belief in these supposed facts before we can rightly appreciate his theory of the mode of action of the syphilitic poison : for instance, if a chancre was only cưrable by mercury, and if mercury cured it by superseding the poison of syphilis, how could he account for the appearance of secondary affections after an interval perhaps of two months. The difficulty is removed if, by supposing that at some uncertain period a portion, however minute, was absorbed into the system, and stamped on certain structures a diseased action that was inevitable after the lapse of a certain time, while the poison itself instantly disappeared. Again, if the smallest conceivable quantity of the syphilitic poison absorbed into the system is sufficient to contaminate it, how could he account for the number of cases of primary syphilis not followed by the constitutional disease? You see that he would be compelled to suppose that the poison was not absorbed at the moment of its application, or at any known period. Mr. Hunter's theory, however, you will observe, accomplished all that can be expected from a theory, namely, that it accounted for the whole range of facts as he supposed them to exist. But I need not remind you of the absurdity of retaining a theory based upon data which have long since been proved to be erroneous.

\section{STATISTICAL REPORT}

OF THE

DISEASES, \&c., OF THE OUT-DOOR PATIENTS

OF THE

\section{ST. MARYLEBONE INFIRMARY,}

FOR THE LAST THREE YEARS.

Presented to the Directors of the Si. Marylebone Infirmary and Workhouse.

By R. Boyd, M.D., Resident Physician, \&c.

The annexed tables are drawn up for the purpose of exhibiting the nature of the diseases, \&c., occurring amongst the out-door poor visited at their own homes, from the St. Marylebone Infirmary, and their results, during a period commencing in the winter of 1838, and ending with the autumn of 1841.

It will be observed that the cases are arranged according to the season in which they have been treated, and the age when they have applied. In this way a comparison can be readily made of the prevalence of disease at different seasons, and at different periods of life, together with the mortality.

For the purpose of affording medical relief, the parish has been divided into two districts, eastern and western; to each of which one medical officer is appointed, whose respective duties consist in prescribing for those who are able to attend at the infirmary, and in visiting those who are unable tó do so at their own homes. 
SUMMARY OF TABLES.

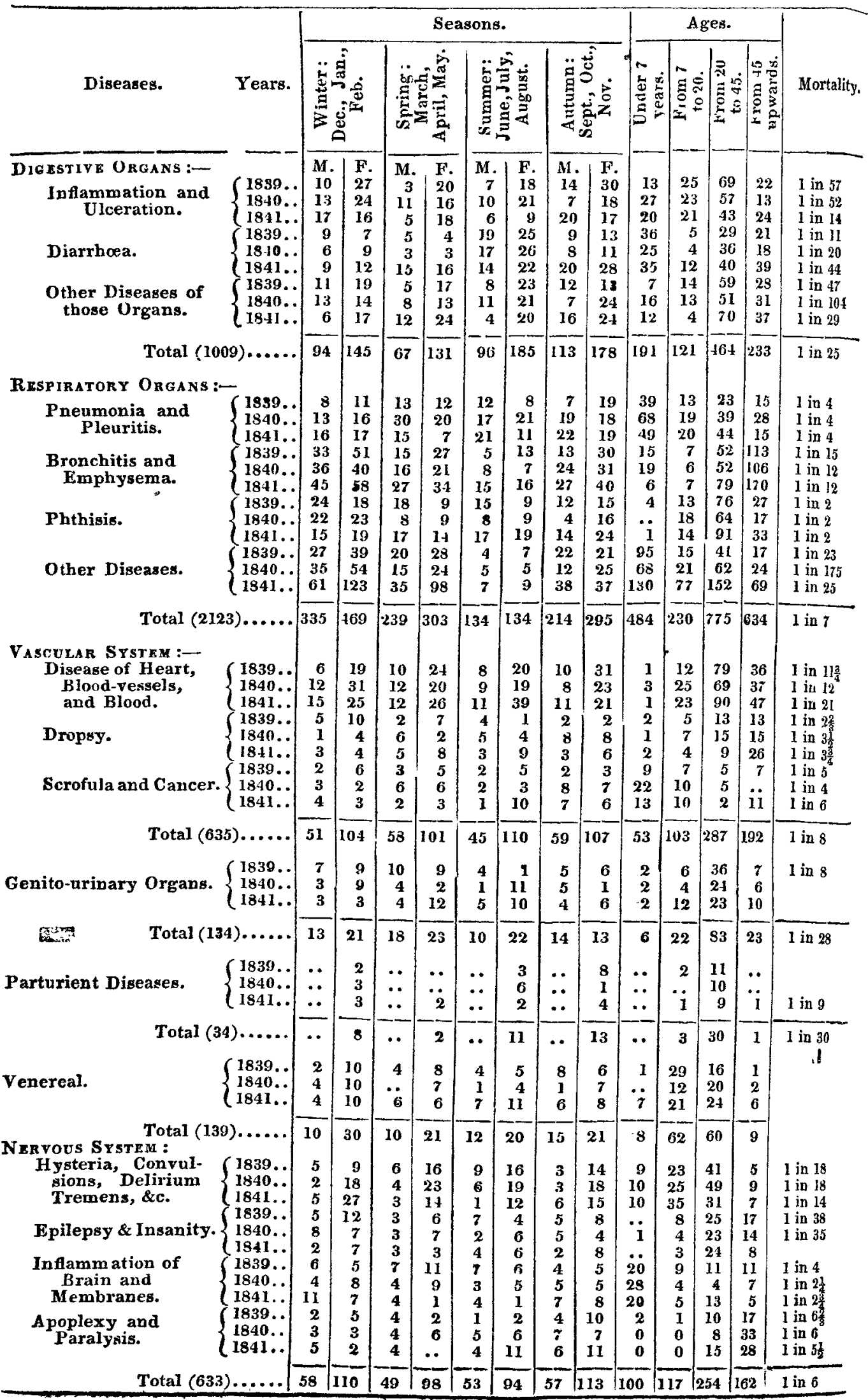


SUMMARY OF TABLES-(Continued).

\begin{tabular}{|c|c|c|c|c|c|c|c|c|c|c|c|c|c|c|}
\hline \multirow{2}{*}{ Diseases. } & \multirow[b]{2}{*}{ Years. } & \multicolumn{8}{|c|}{ Seasons. } & \multicolumn{4}{|c|}{ Age. } & \multirow[b]{2}{*}{ Mortality. } \\
\hline & & \multicolumn{2}{|c|}{ 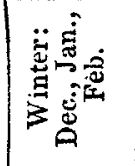 } & \multicolumn{2}{|c|}{ 品它完 } & \multicolumn{2}{|c|}{ 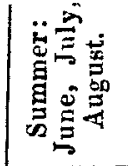 } & \multicolumn{2}{|c|}{ 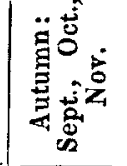 } & 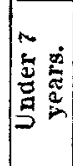 & 若 & 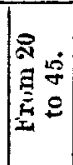 & 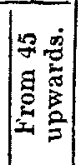 & \\
\hline Locomotive ORgaNs: & & M. & F. & M. & F. & M. & F. & & F. & & & & & \\
\hline Injuries and Jis- & 1839 & 12 & 18 & 15 & 16 & 20 & 4 & 13 & 15 & 4 & 17 & 53 & 39 & 1 in 95 \\
\hline eases of Bones & 1840. & 22 & 12 & 16 & 17 & 15 & 14 & 19 & 16 & 14 & 28 & 42 & 47 & 1 in 36 \\
\hline and Joints. & $1841 \ldots$ & 19 & 16 & 15 & 13 & 18 & 22 & 11 & 10 & 5 & 26 & 60 & 33 & 1 in 111 \\
\hline Injuries and Dis- & 1839 & 20 & 24 & 17 & 26 & 9 & 15 & 12 & 28 & 17 & 26 & 61 & 47 & l. in 134 \\
\hline eases of Cellular & $1840 .$. & 9 & 32 & 15 & 11 & 14 & 10 & 17 & 22 & 21 & 27 & 40 & 42 & 1 in 30 \\
\hline Tissue. & $1841 \ldots$ & 11 & 19 & 11 & 28 & 12 & 15 & 21 & 36 & 10 & 20 & 75 & 45 & \\
\hline \multirow{3}{*}{$\begin{array}{c}\text { Rheumatism and } \\
\text { Gout. }\end{array}$} & $1839 .$. & 36 & 29 & 32 & 27 & 15 & 16 & 11 & 12 & 1 & 16 & 68 & 93 & 1 in 74 \\
\hline & $1840 \ldots$ & 42 & 23 & 31 & 21 & 17 & 20 & 28 & 31 & .. & 17 & 99 & 97 & 1 in 178 \\
\hline & $18+1 \ldots$ & 60 & 30 & 32 & 22 & 33 & 26 & 31 & 28 & .. & 23 & 117 & 117 & 1 in 110 \\
\hline \multirow{4}{*}{ Skin. } & ...... & 231 & 203 & 184 & 181 & 153 & 142 & 160 & 198 & 78 & 205 & 615 & 560 & 1 in 73 \\
\hline & $1839 \ldots$ & 5 & 8 & 7 & 5 & 1 & 3 & 4 & 13 & 19 & 13 & 13 & 1 & \\
\hline & $1840 \ldots$ & 4 & 11 & 7 & 10 & 8 & 5 & 5 & 13 & 31 & 18 & 7 & 7 & \\
\hline & $1041 \ldots$ & 7 & 15 & 9 & 8 & 3 & 4 & 4 & 6 & 25 & 10 & 13 & 8 & \\
\hline \multicolumn{2}{|c|}{ Total (165)...... } & 16 & 34 & $\mathbf{2 3}$ & 23 & 12 & 12 & 13 & 32 & 75 & 41 & 33 & 16 & \\
\hline \multicolumn{2}{|l|}{ Eruptive Fevers :- - } & & & & & & & & & & & & & \\
\hline \multirow{4}{*}{ Erysipelas. } & & 2 & 6 & $\mathbf{1}$ & 10 & 2 & 4 & 2 & 4 & 2 & 5 & 17 & 7 & 1 in 12 \\
\hline & $1840 \ldots$ & 4 & 4 & 3 & 4 & 2 & 7 & 5 & 10 & 5 & 4 & 21 & 9 & \\
\hline & & 4 & 8 & 4 & 3 & 3 & 3 & 1 & $\mathbf{8}$ & 2 & 6 & 13 & 13 & \\
\hline & 1839. & 1 & 6 & 15 & 22 & 20 & 19 & 27 & 27 & 127 & 9 & .. & $\mathbf{1}$ & 1 in 45 \\
\hline \multirow[t]{3}{*}{ Measles. } & $1840 .$. & 3 & I & 1 & .. & 1 & 3 & 1 & 5 & 13 & 1 & 1 & .. & 1 in \\
\hline & 11.. & 10 & 5 & 7 & 7 & 14 & 14 & 19 & i5 & 57 & 27 & 6 & 1 & \\
\hline & $1839 \ldots$ & 13 & 18 & 20 & 29 & 35 & 35 & 8 & 8 & 145 & 17 & 2 & 2 & 1 in 17 \\
\hline \multirow[t]{3}{*}{ Scarlatina. } & $1840 .$. & 4 & 13 & 12 & 12 & 15 & 22 & 5 & 5 & 53 & 23 & 12 & .. & 1 in 16 \\
\hline & & 5 & 3 & 7 & 14 & 7 & 12 & 21 & 22 & 57 & 32 & 2 & .. & 1 in 6 \\
\hline & & 6 & 2 & 2 & 4 & 3 & 1 & $\mathbf{3}$ & 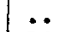 & 16 & 4 & 1 & .. & 1 int $3 \frac{1}{2}$ \\
\hline \multirow[t]{2}{*}{ Small-pox. } & $1840 \ldots$ & 3 & $\mathbf{3}$ & 3 & $\mathbf{3}$ & o & 5 & 19 & 16 & 50 & 7 & 1 & $\ldots$ & 1 in 5 \\
\hline & & 16 & 29 & 4 & 6 & I & 3 & 5 & 4 & 52 & 13 & $\mathbf{3}$ & $\cdots$ & 1 in $3 \frac{1}{2}$ \\
\hline \multicolumn{2}{|c|}{ Total (839) ...... } & 71 & 98 & 79 & 113 & 109 & 129 & 116 & 124 & 579 & 148 & 79 & 33 & 1 in 10 \\
\hline \multirow{3}{*}{ Fever. } & $1839 \ldots$ & 42 & 53 & 54 & 66 & 34 & 51 & 29 & 50 & 79 & 88 & 175 & 37 & 1 in 18 \\
\hline & & 38 & 36 & 20 & 29 & 36 & 37 & 32 & 35 & 66 & 76 & 92 & 29 & 1 in 19 \\
\hline & & 62 & 94 & 38 & 50 & 49 & 60 & 42 & 65 & 117 & 107 & 181 & 55 & 1 in 22 \\
\hline \multicolumn{2}{|c|}{ Total (1102),..... } & 142 & 183 & 112 & 145 & 119 & 148 & 103 & 150 & 262 & 271 & 148 & 121 & 1 in 19 \\
\hline \multirow{3}{*}{$\begin{array}{l}\text { Debility, Destitu- } \\
\text { tion, Unknown } \\
\text { Causes, \&c. }\end{array}$} & $1839 \ldots$ & 3 & 15 & .. & 5 & 2 & 4 & $\mathbf{I}$ & $\mathbf{9}$ & 1 & 5 & 8 & 25 & 1 in 25 \\
\hline & $1810 \ldots$ & 1 & 11 & 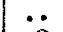 & 7 & 2 & 5 & 4 & 6 & 2 & 2 & 10 & 22 & 1 in $15 \frac{1}{2}$ \\
\hline & $18+1 \ldots$ & 3 & 11 & 2 & 20 & .. & 5 & 2 & 7 & 1 & 2 & 17 & 30 & 1 in 15 \\
\hline \multicolumn{2}{|c|}{ Total (125) ...... } & 7 & 37 & 2 & 32 & 4 & 14 & 7 & 22 & 4 & 9 & 35 & 77 & 1 in 11 \\
\hline Aggregate (83 & & 1034 & 1447 & 839 & 1178 & 739 & 1023 & 871 & 1265 & 1862 & 1342 & 2153 & 32039 & 1 in 13 \\
\hline
\end{tabular}

The population of the parish, according to was from 20 to 45 . Inflammation of the the census of the past year, was 139,454 . lungs carried off 71 , principally children The average number of paupers receiving under seven. Next to chest diseases, the parochial relief during the year was 5679 ; greatest mortality occurred among the sufof this number, 4050 received out-door relief; ferers from eruptive fevers, small-pox, 1353 were inmates of the workhouse, and measles, and scarlet fever, and again it fell 276 inmates of the infirmary.

The number of males in the table is 3483 ; vailed during the autumn and winter of females, 4913 -total, 8396 : of this number, 1840, and the winter of 1841. Measles pre1180 were admitted to the infirmary, Small- vailed from the spring of 1839 to the autumn pox Hospital, and a few to other hospitals; of 1840 ; and it is curious to observe, that leaving 7216, which were attended at their the ordinary laws governing epidemics have own homes, among whom 561 died, being been departed from; the mortality was a proportion of rather less than 1 in $\mathbf{1 3}$.

The mortality, as shown in the table, has ence of severity of the visitations of scarlet been greatest among those suffering from fever is worthy of notice. In 1841 the mordiseases of the lungs; the number of tality was 1 in 6 , whilst in the other two deatbs from consumption being 100, and years it was 1 in 16 , and 1 in 17 .

the age at which it was most prevalent Among the diseases of the brain it will be 
seen that the mortality has fallen heavily on children under seven, in the form of inflammation of the brain and convulsions.

Among the diseases of the vascular system, one would almost be disposed to place twelve deaths from apoplexy, disease of the heart and blood-vessels being so frequently combined. The deaths from enlarged heart were 16 ; from dropsy, frequently combined with diseased heart, 25.

The deaths from fever amounted to 47 , but the number of cases was unequally divided; in the year 1841, they were nearly double those of 1840 , while those of 1840 were onethird less than 1839.

The mortality among diseases of the digestive organs was 36 ; it fell principally among the very young, and the old in the form of diarrhoea. From scrofula there were fifteen deaths.

The number of cascs in the year 1839 amounted to 2609 ; in the year 1810 to 2631 , and in the year 1841 to 3156 , being an increase of 525 .

The total expenditure for 1841 was $4305 l$. 18s. 11d. Arerage number of paupers receiving daily medical relief as follows:Patients in the infirmary, 230; patients visited at home, 136 ; prescribed for at the infirmary, 163; workhouse patients, 102 : $t_{\text {otal, }} 631$, being an increase of 92 patients on the year 1840 , as inay be seen by reference to the report in THE LANCET of 18th December last, vol. i., 1841-2. The expenditure for drugs, $531 l .3 \mathrm{~s} .9 \mathrm{~d}$.; for wine and spirits, $178 \mathrm{l} .9 \mathrm{~s} .5 \mathrm{~d}$; for surgical instruments, 77l. 14s. 1d.; salaries to medical officers, 369l. 8s.6d.; nurses' wages, 288l. 8s. 6d.: total, 1445l. 4s. 3d., being a decrease of 5l. 13s. 1d. compared with the preceding year.

\section{Localities and Places of Residence of the Poor.}

Although there are such a number of medical charities in Condon, still the amount of relief they afford to the strictly-speaking pauper population, is much less than might be expecter, especially in certain localities ; a number of the inhabitants of which are strangers, ignorant of the necessary forms of application for assistance, as no uniform system is adopted at such places, each being governed by its own peculiar by-laws, known only to the few.

To give some idea of the places of abode and manner of living of a large portion of the pauper population, especially in the eastern division of the parish, it may not be considered out of place to state a few facts. Situate in the immediate vicinity of Portmansquare is a court called "Calmel Buildings," which is principally inhabited by the lower orders of the Irish, the "Hivites" of the metropolis. 'This locality is not chosen as affording a solitary instance of the wretched accommodation and the degraded state of society that necessarily follow amongst this unfortunate class, for the parish contains other localities worse situ. ated in every respect than the one above mentioned. Thus, "Gee-court" in the same neighbourhood, leading out of Oxford-street. is one of the principal thoroughfares of London, and in which occasionally such $e x$. treme cases of destitution and disease have occurred, as would scarcely be credited.

Calmel-buildings affords a good example of an almost purely pauper population; and as regards medical relief, one which is con. fined more to that received from the work house than perhaps any other of an equal extent in the parish. This court is narrow, about twenty-three feet in breadth; the houses are three stories in height, surrounded and overtopped by the adjacent buildings; the drainage is most deficient, a common sewer rumning down the centre of the court; the receptacle for slops, \&c., from the houses on both sides. The lower apartment, especially the kitchens, which are under ground, are damp and badly ventilated, light and air being admitted through a grating on a level with the court. At all times, but particularly during the winter, in many of them, a most offensive effluvium is constantly emanated, so much so, as to produce quite a sickening effect on the visitor. The houses are twenty-six in number, rented at an annual sum of from 25l. to 30l.; each contains ten rooms, which the renters of houses let out to families or individuals, who, in their turn, in many instances, receive as lodgers those who are unable to bear the expense of a room. By such means they pay, two or three hundred "per cent." is added to the original rent.

According to the census of last year, the number of inhabitants were 944 ; of whom 426 were males, and 518 females: of this number, 178 were children under 7 years of age; 200 from 7 to 20 years; 457 from 20 to 45 ; and 109 from 45 years and upwards. The number of persons in one house varied from 2 to 70 ; one house was unoccupied. Occupatious of the above, as follows :-

\section{Males.}

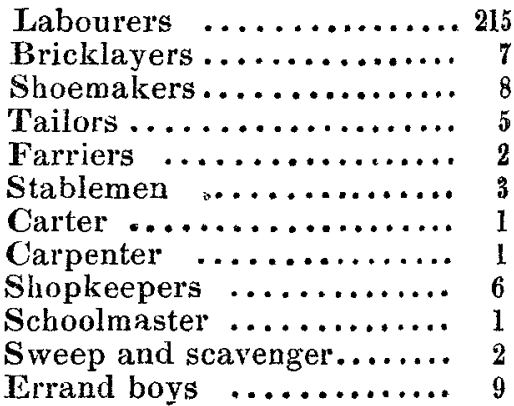

Females.

Servants ............ 51

Marketwomen.......... 37

Milk-carriers ............ 34 
Charwomen............. 21

Washerwomen $. . . \ldots \ldots \ldots . .10$

Sempstresses ............ 10

Number of the males, 261 ; and of the females, 163. Total number of the working population 424, leaving 520 without any oc- cupation; the greater part of whom were children and old persons unfit to makc any exertion for themselves, and depending solely on the industry of the others, a large number of whom, particularly the labourers, are frequently unemployed during the year.

The number of cases atlended in cach part of the house and results, were as follows:-

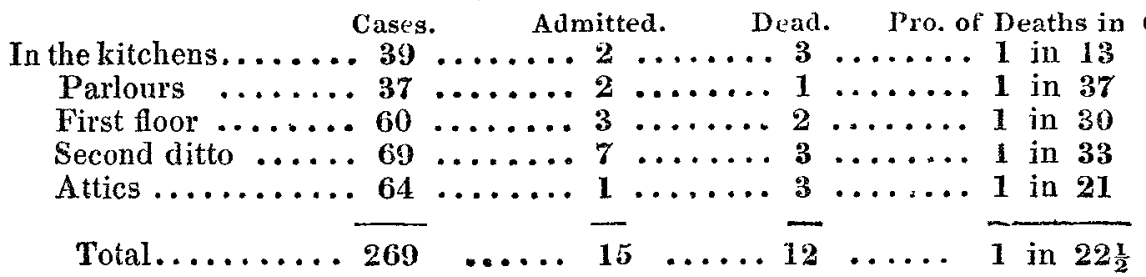

The mortality has been greatest amongst the occupants of kitchens. The cases have, however, not been so numerous in the kitchens and parlours as in other parts of the house, owing to a smaller number being inhabited, some of the latter being occupied as shops, and the former as store-rooms, and in one or two instances the lower part of the house being converted into stables.

\section{REPORT}

$\mathrm{OF}$

\section{PRIVATE MEDICAL PRACTICE}

\section{FOR 1840 .}

By Chardes Cowan, M.D., E. and P., Physician to the Royal Berkshire Hospital and Reading Dispensary, F.S.S., \&c.

(Continued from p.363.)

DISEASES OF THE RESPIRATORY SYSTEM. PHTHISIS.

of the 53 cases, 31 were males; 23 females. 65.

Ages.-The youngest was 15 ; the oldest

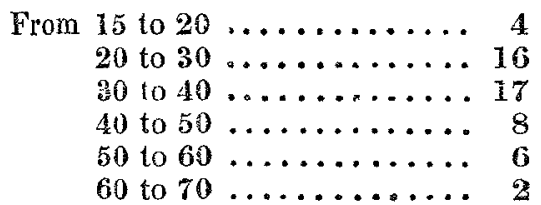

Occupations.-Sempstresses, 5; agricul. tural labourers, 7 ; domestics, 5 ; bakers, 3 . The remainder were units, or had no occupation.

Hereditary Influence.-Out of 16 cases reported, 13 were afirmative, 3 negative. In some families all the childrea were suc. cessively cut of, while the parents seemed exempt.

Locality of Deposit. - In 20 at the time of application, it could only be detected on the right side; in 7 on the le/t. In 13 it existed on both sides, but was most extensive on the right. It preponderated on the left side in only two instances; in 9 the deposit seemed equal on both sides. These results are opposed to Louis and other observers, who have found the left lung most frequently afrected. In no instance did the deposit deviate from the usual course of advancing from the summit to the base of the lung.

\section{Anterior Duration.}

From 1 to 6 months ...... 23

6 to 12 months ....... 13

1 to 2 years........ 13

2 to 4 years......... 2

4 to 5 years......... 2

Symptoms.-The most uniform in the order of frequency were, cough, emaciation, night sweats, dyspnoea, and debility. Iæ moptysis was present in 18 , and was copious only in 2 ; diarrhoea existed in 7 cases; in 2 the larynx was affected, and the peculiar husky, woolly character of the voice was observed in several. Pain was seldom mentioned.

Causes.-Exposure to wet and cold, hereditary influence, deficient food, and sedentary habits.

Result.-Relieved, 10; irregular,

32 ; known to have died, 11.

Treatment. - It was in principle the same in all : a combination of quinine and steel, with sedatives, occasional leeching, blisterincs, or stimulating liniments; good but not stimulating diet; exercise on foot or horseback, and change of climate when practicable; opiates at night for the cough, and when the deposit was not extensive, and the general strengin not much impaired, emetics were freely used, and with temporary advantage. The relief experienced was in some cases very great; in others they could not be continued. The progress of disease appeared to be often retarded, and much relief for a time afforded in the majority of cases, but we caunot boast, with our more fortunate contemporaries, of any curative results. The great majority were chronic hopeless cases, irregular in attendance, and among the poorer classes.

Our present impression as to the efficacy of treatment in consumption is, that the disease is almost uniformly fatal, but that a tonic invigorating system, combined with 